\title{
Assessment of a natural, non-antibiotic blend on performance, blood biochemistry, intestinal microflora, and morphology of broilers challenged with Escherichia coli
}

\author{
Milad Manafi ${ }^{1}$, Mahdi Hedayati ${ }^{1}$, Saeed Khalaji ${ }^{1}$, Mohammad Kamely ${ }^{2}$ \\ ${ }^{1}$ Malayer University, Faculty of Agricultural Sciences, Department of Animal Science, Malayer, Iran. \\ ${ }^{2}$ Tarbiat Modares University, Faculty of Agriculture, Department of Poultry Science, Tehran, Iran.
}

\begin{abstract}
The effect of a non-antibiotic growth-promoting component composed of natural phytomolecules, directfed microbials, glucomannan oligosaccharides, and organic acids on the performance, intestinal morphology and microbiology, plasma biochemistry, enzyme activities, visceral organ weights, and immune response of commercial broilers challenged with Escherichia coli was investigated. Three hundred and sixty one-day old male Ross 308 broiler chicks were randomly divided into basal diet (control, CON); control plus $0.5 \mathrm{~mL}$ of culture materials containing $10^{8} \mathrm{cfu} / \mathrm{mL}$ of $E$. coli (E. coli); control with $400 \mathrm{mg} / \mathrm{kg}$ bacitracin methylene disalicylate (an antibiotic growth promoter, AGP); control plus $1000 \mathrm{~g} / \mathrm{t}$ of feed of a blended mixture of natural feed additives (NAT); combination of E. coli and AGP treatments (E. coli + AGP); or the combination of E. coli and NAT treatments $(E$. coli + NAT). E. coli injection decreased broiler performance by lowering body weight and increasing feed intake, whereas AGP and NAT treatments improved body weight and the feed efficiency when compared to the other groups. However, feed intake was not affected by treatment. Immune response also improved with the addition of NAT, compared with control. Blood biochemistry parameters were significantly affected by the treatments. Nutrient digestibilities were increased by AGP and NAT supplementation in E. coli-challenged groups. Both AGP and NAT significantly decreased $E$. coli and coliform numbers in ceca. Ileal villus height was not affected by treatment, but ileal crypt depth and goblet cell counts decreased in the NAT relative to control group. Antibiotic growth promoter was somewhat more effective in improving broiler growth and health characteristics than NAT, but since NAT generally improved broiler performance compared to the control group, it can be alternatively used as an alternative to AGP in commercial broiler production.
\end{abstract}

Key Words: body weight, challenge, chicks, natural feed additive

\section{Introduction}

The banning of antibiotic growth promoters (AGP) in many countries (Attia et al., 2011) has dramatically decreased the use of AGP as feed additives over the past decade (Demir et al., 2005; Ghosh et al., 2012). This has been accompanied by worsened animal health, for example in terms of increased severe diarrhea symptoms, weight loss, and mortality due to infection with Escherichia coli and clostridial necrotic enteritis (Casewell et al., 2003; Attia et al., 2011). There are many reports stating that potential feed additives, which could be considered as alternative to AGP, include probiotics or direct-fed microbials (DFM), yeast-derived components, vitamin metabolites, plant extracts, acidifiers and organic acids, prebiotics,

Received January 27, 2016 and accepted August 1, 2016.

Corresponding author: manafim@malayeru.ac.ir

http://dx.doi.org/10.1590/S1806-92902016001200003

Copyright (C) 2016 Sociedade Brasileira de Zootecnia. This is an Open Access article distributed under the terms of the Creative Commons Attribution License (http://creativecommons.org/licenses/by/4.0/), which permits unrestricted use, distribution, and reproduction in any medium, provided the original work is properly cited. bacteriocins, bacteriophages, antimicrobial peptides, and dietary enzymes (Lee et al., 2004; Cross et al., 2007; Diarra et al., 2007; Biggs and Parsons, 2008; Applegate et al., 2010; Jayaraman et al., 2013; Salim et al., 2013; Zhang and Kim, 2014).

A number of bacteria like Lactobacillus, Lactococcus, Bifidobacterium, Streptococcus, Enterococcus, and Saccharomyces cerevisiae are regularly used as DFM in poultry diets (Lee et al., 2003; Salim et al., 2013). Previous literature has confirmed that some bacteria species are capable to directly prevent avian pathogenic E. coli (Lee et al., 2003; Amerah et al., 2013). Fructooligosaccharides and mannan oligosaccharides (MOS) beneficially affect gut health by suppressing enteric pathogens, enhancing immune responses, and improving the integrity of the intestinal mucosa of broilers (Baurhoo et al., 2007). Mannan oligosaccharides can join E. coli and Salmonella and prevents these pathogens from sticking to the intestinal wall (Bovera et al., 2012; Shanmugasundaram et al., 2013). Organic acids are also potential feed additive alternatives to AGP in animal rearing systems (Adil et al., 2011; Sultan et al., 2015). Organic acids maintain cellular integrity of 
the gut lining and improve digestive processes by helping to maintain normal gut flora. Citric and formic acids can enhance the digestibility of proteins and amino acids by increasing gastric proteolysis (Sultan et al., 2015). Moreover, in poultry industry, they have been frequently studied as a tool to lessen undesirable bacteria and among them, formic acid has been revealed to be principally effective against E. coli (Gaskins et al., 2002). In addition, the application of plant bioactive compounds like thymol, carvacrol, cinnamaldehyde, and limonene is assumed as substitute to the use of AGP (Applegate et al., 2010). Carvacrol and thymol, the two main constituents of essential oils (EO) derived from oregano and thyme, as well as allicin (from garlic) and peppermint, have antimicrobial, antioxidant, and antiseptic properties (Jang et al., 2007). The most abundant constituent of peppermint EO is menthol, which has antibacterial activity (Toghyani et al., 2010). The results of the addition of plant extracts in the diet on the growth performance of broilers are controversial (Garcia et al., 2007; Jang et al., 2007; Brenes and Roura, 2010).

This current experiment was conducted to evaluate the potential use of a commercial blend $\left(\mathrm{Natusol}^{\circledR}\right.$ ) of phytomolecules, DFM, glucomannan oligosaccharides, and organic acids in broiler diet as a possible alternative to AGP in chicks challenged by $E$. coli; the growth performance, intestinal morphology and microbiology, blood enzymes and biochemical parameters, immune responses against antibodies, and weights of relative organs of broilers were assessed.

\section{Material and Methods}

Three hundred and sixty one-day-old male Ross 308 chicks were procured from a hatchery and grown for 42 days according to Malayer University Approved Animal Care Rules and Protocols. The chicks were reared in thermostatically controlled pens in an environmentally controlled building. Experiment was conducted in a completely randomized manner with six treatments and five replicates using 12 chicks for each replicate (pen). Experimental treatments included: CON: control group, fed a basal diet; E. coli: control plus $0.5 \mathrm{~mL}$ of culture containing $10^{8} \mathrm{cfu} / \mathrm{mL}$ of $E$. coli; AGP: control plus 400 $\mathrm{mg} / \mathrm{kg}$ bacitracin methylene disalicylate; NAT: control plus a dietary blend of direct-fed microbials (DFM), phytomolecules, glucomannan oligosaccharides, and organic acids ( $1000 \mathrm{~g} / \mathrm{t}$ of feed $) ; E$. coli + AGP: combination of E. coli and AGP group treatments; E. coli + NAT: combination of $E$. coli and NAT group treatments. The "NAT" employed in this study was Natusol ${ }^{\circledR}$ (a combination of phytomolecules: allicin, peppermint, thymol, and carvacrol; DFMs: Bacillus coagulans, B. subtilis, and B. licheniformis; organic acids: propionic and fumaric acids; and glucomannan oligosaccharides), provided by Zeus Company Biotech Limited, Mysore, India. The pathogenic strain of $E$. coli used for experimental challenge of the birds was serotype PTCC-1399, a kind gift from the Iranian Research Organization for Science and Technology. This bacterium was isolated from affected organs and feces of clinical cases of birds that showed clear signs of general colibacillosis. The challenge inoculum was prepared according to Quinn et al. (1994). At 10 days old, each chicken in the infected groups was intramuscularly (i.m.) injected with $0.5 \mathrm{~mL}$ of nutrient broth culture containing $10^{8}$ colony forming units (cfu)/mL of $E$. coli, after overnight growth of bacteria without washing. Intramuscular injection was done into the right breast muscle of the birds (Fernandez et al., 2002). During the study, all birds were brooded by standard temperatures, which were gradually reduced from 32 to $24^{\circ} \mathrm{C}$, and under a 23L:1D lighting cycle. The basal diets were prepared to meet or exceed Ross 308 male broiler specifications for macro- and micronutrients (Table 1). Body weight (BW) and feed intake (cumulative) were taken and feed conversion ratio (FCR) was calculated at the end of experiment.

Table 1 - Ingredients and composition of the basal diets in different periods of the experiment

\begin{tabular}{lccc}
\hline \multirow{2}{*}{ Diet composition $(\mathrm{g} / \mathrm{kg})$} & Starter & Grower & Finisher \\
\cline { 2 - 4 } & $(1-14$ days $)$ & $(14-28$ days $)$ & $(28-42$ days $)$ \\
\hline Corn $(8 \% \mathrm{CP})$ & 545.5 & 540 & 567 \\
Soybean meal $(43 \% \mathrm{CP})$ & 401 & 390 & 360 \\
Soybean oil & 11 & 33.2 & 39 \\
Calcium carbonate & 10.6 & 8.9 & 8.7 \\
Dicalcium phosphate & 19.1 & 17.3 & 15.7 \\
DL-methionine & 3 & 2.1 & 1.6 \\
L-lysine & 1.3 & 0 & 0 \\
Vitamin premix & 2.5 & 2.5 & 2.5 \\
Mineral premix & 3.5 & 2.5 & 2.5 \\
NaCl & 2.5 & 3.5 & 3
\end{tabular}

Calculated chemical composition

$\begin{array}{llll}\text { Metabolizable energy }(\mathrm{MJ} / \mathrm{kg}) & 11.76 & 12.47 & 12.76\end{array}$

$\begin{array}{llll}\text { Crude protein }(\mathrm{g} / \mathrm{kg}) & 215 & 210 & 200\end{array}$

$\begin{array}{llll}\mathrm{Ca}(\mathrm{g} / \mathrm{kg}) & 9.7 & 8.6 & 8.1\end{array}$

Available phosphorous (g/kg) $\quad 4.6 \quad 4.3 \quad 4$

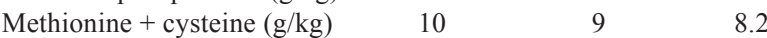

$\begin{array}{lrrr}\text { Lysine }(\mathrm{g} / \mathrm{kg}) & 13.2 & 11.9 & 11.1\end{array}$

${ }^{1}$ Dicalcium phosphate contained $16 \%$ phosphorous and $23 \%$ calcium.

2 Vitamin premix per $\mathrm{kg}$ of diet: vitamin A (retinol), $2.7 \mathrm{mg}$; vitamin $\mathrm{D}_{3}$ (cholecalciferol), $0.05 \mathrm{mg}$; vitamin $\mathrm{E}$ (tocopheryl acetate), $18 \mathrm{mg}$; vitamin $\mathrm{K}_{3}, 2 \mathrm{mg}$; thiamine, $1.8 \mathrm{mg}$; riboflavin, $6.6 \mathrm{mg}$; pantothenic acid, $10 \mathrm{mg}$; pyridoxine, $3 \mathrm{mg}$; cyanocobalamin, $0.015 \mathrm{mg}$; niacin, $30 \mathrm{mg}$; biotin, $0.1 \mathrm{mg}$; folic acid, $1 \mathrm{mg}$; choline chloride, $250 \mathrm{mg}$; antioxidant (Ethoxyquin), $100 \mathrm{mg}$.

${ }^{3}$ Mineral premix per $\mathrm{kg}$ of diet: $\mathrm{Fe}\left(\mathrm{FeSO}_{4} \cdot 7 \mathrm{H}_{2} \mathrm{O}, 20.09 \% \mathrm{Fe}\right), 50 \mathrm{mg} ; \mathrm{Mn}$ $\left(\mathrm{MnSO}_{4} \cdot \mathrm{H}_{2} \mathrm{O}, 32.49 \% \mathrm{Mn}\right), 100 \mathrm{mg} ; \mathrm{Zn}(\mathrm{ZnO}, 80.35 \% \mathrm{Zn}), 100 \mathrm{mg} ; \mathrm{Cu}\left(\mathrm{CuSO}_{4} .5 \mathrm{H}_{2} \mathrm{O}\right)$ $10 \mathrm{mg}$; I (KI, 58\% I), $1 \mathrm{mg}$; $\mathrm{Se}\left(\mathrm{NaSeO}_{3}, 45.56 \% \mathrm{Se}\right), 0.2 \mathrm{mg}$.

$\mathrm{CP}$ - crude protein. 
The Malayer Branch of Iranian Veterinary Organization suggested the following obligatory vaccinations, which were modified by a Malayer University veterinarian:

Spray of Newcastle disease (ND) vaccination was performed in the hatchery and was repeated on day 12 through drinking water $\left(\mathrm{CEVAC}^{\circledR} \mathrm{B} 1\right.$ containing the Hitchner B1 strain of freeze-dried, live Newcastle disease virus), with a booster on the 20th day as clone30 (HIPRAVIAR $^{\circledR}$ ) in the drinking water. Vaccination for infectious bronchitis (IB) was carried out twice: first, as a spray at the beginning of the experiment and second, as a booster in the drinking water on the 10th day (H-120, CEVAC $\left.^{\circledR}\right)$. Vaccination against infectious bursal disease (IBD) was given two times: first on day 15 and another on day 24 (Gambo-L, CEVAC $\left.{ }^{\circledR}\right)$ through drinking water. At day 21, the booster B1 neurotropic vaccine strain virus $(\mathrm{ND} 6 / 10)\left(\mathrm{CEVAC}^{\circledR}\right)$ was provided in drinking water, after performing a hemagglutination inhibition titer test for ND and enzyme-linked immunosorbent assay (ELISA) technique for IB and IBD titers to determine levels of antibodies.

On day 42 , two chicks of each replicate ( $\mathrm{n}=8 /$ treatment) were randomly chosen and blood samples were taken in heparinized tubes by puncturing the brachial vein. These blood samples were used to measure the levels of plasma albumin, globulin, triglyceride, cholesterol, high-density lipoprotein (HDL), low-density lipoprotein (LDL) and the activities of alanine amino transaminase (ALT), $\gamma$-glutamyl transferase (GGT), and alkaline phosphatase (ALP). The concentrations of triglyceride, total cholesterol, HDL, and LDL in the plasma samples were analyzed with an automatic biochemical analyzer (Hitachi 704 Automatic Clinical Chemistry Analyzer, Boehringer Mannheim Company, Ingelheim am Rhein, Germany) using colorimetric methods. Plasma was used for determination of albumin and globulin concentrations according to procedures described by Corzo et al. (2009). The activities of ALT, GGT, and ALP were measured with an Automatic Biochemical Analyzer (Hitachi 717, Boehringer Mannheim Company) using an Elitech Diagnostic kit (catalog No. A.110537).

At day 42 , four birds were randomly selected from each treatment group, stunned, and killed (euthanasia through cervical dislocation). The internal organ weights of liver, kidney, pancreas, cloacal bursa, heart, and spleen were measured and expressed as $\mathrm{g} / \mathrm{kg}$ of BW. Then, the digestive tracts with contents were collected aseptically and the $1 \mathrm{~cm}$ ileum was detached from the Meckel's diverticulum, proximal to the ileocecal junction. A 2-cm section of ileum was taken from the mid of the ileum and flushed gently with PBS buffer ( $\mathrm{pH}$ 7.2). Tissue sections were instantly fixed in $10 \%$ neutral buffered formalin and changed for three times to complete the fixation procedure. A single 0.5-cm sample was separated from ileal section, dehydrated with ethanol concentrations $(70,80,95$, and $100 \%)$, cleared with xylene, and placed into POLYFin ${ }^{\mathrm{TM}}$ embedding wax. Tissue sections $(2 \mu \mathrm{m})$ were cut by microtome (Leitz-1512 Microtome, Wetzlar, Germany), floated onto slides, and stained with hematoxylin (H\&E) (Gill no. 2; Sigma, St. Louis, MO) and eosin (Sigma). Twelve images were taken from four tissue sections of each ileal section using a digital camera under light microscopy and a total of 24 villus heights and crypt depths were measured using imaging software. Measurements of villus length were taken from the tip of the villus to the valley between individual villi and measurements of crypt depth were taken from the valley between individual villi to the basolateral membrane. The number of goblet cells in $1 \mathrm{~mm}$ of villus length was also recorded (Xu et al., 2003).

All sample diets were ground in 1-mm screen in a Wiley mill prior to dry matter (DM), crude protein $(\mathrm{CP})$, gross energy (GE), and crude fat (CF) analysis (AOAC, 2003). For apparent total tract digestibility, $\mathrm{Cr}_{2} \mathrm{O}_{3}$ (Dichromium trioxide) $(0.2 \%)$ was added into the diets as an indigestible marker from d 35 to 42 . Digestibility of the nutrients and energy were calculated by the method described by Hahn et al. (2006). During d 38 to 42, fresh feces from two chicks in the same pen were collected, pooled, and frozen until being lyophilized and ground. Feces and feed samples were ground in a 1-mm screen and later used to determine DM content by oven-drying at $105{ }^{\circ} \mathrm{C}$ for $24 \mathrm{~h}$. Nitrogen (N) content of the diets was determined by the combustion method (Model FP2000; Leco Corp., St. Joseph, MI) according to the AOAC (2000) and GE was determined by adiabatic bomb calorimetry (Model 1261; Parr Instrument Co., Moline, IL). Chromium was determined by UV absorption spectrophotometry (Shimadzu UV-1201; Shimadzu, Kyoto, Japan) and digestibility of DM following the method described by Williams et al. (1962).

From the aforementioned slaughtered birds, individual cecal contents were pooled to prepare serial dilution. Microbial populations were counted before inoculation onto petri dishes of sterile agar by serial dilution $\left(10^{-4}\right.$ to $\left.10^{-6}\right)$ of cecal samples in anaerobic diluents, according to Bryant and Burkey (1953). E. coli was grown in eosin methylene blue agar, Salmonella in Salmonella-Shigella agar (Merck, Germany), and coliforms in MacConkey agar (Darmstadt, Germany). E. coli bacteria were incubated aerobically at $37{ }^{\circ} \mathrm{C}$. Colonies were counted between 24 and $48 \mathrm{~h}$ after incubation. Colony forming units are defined as distinct colonies measuring $1 \mathrm{~mm}$ in diameter. Then, nine sterile 
test tubes with lids containing $9 \mathrm{ml}$ of phosphate buffer solution as diluent were prepared. Approximately $1 \mathrm{~g}$ of the cecal contents, taken by sterile swab and homogenized for $3 \mathrm{~min}$ before transferring to microbiology lab in cold condition (Bryant and Burkey, 1953) and mixed employing aseptic technique, was added to the tubes and diluted up to $10^{9}$. Later, $1 \mathrm{~mL}$ of contents of each test tube was transferred to one of three selective agar media in petri plates, respectively, and each petri plate incubated in $37^{\circ} \mathrm{C}$ for $24 \mathrm{~h}$. Finally, the intestinal bacterial colony populations formed in each plate was counted and adjusted to X $10^{9}$ manually and then was reported.

Data were analyzed according to a completely randomized design using the GLM procedure of SAS software (Statistical Analysis System, version 9.2). Differences between treatment means were tested using Duncan's multiple comparison test. Statistical significance was declared at $\mathrm{P}<0.05$.

\section{Results}

Body weights (BW) at d 14 were significantly affected by the treatments $(\mathrm{P}<0.05)$ (Table 2$)$. Dietary AGP and NAT supplementation remarkably increased the BW of broilers over the entire experimental period $(\mathrm{P}<0.01)$. The E. coli infected group had the lowest BW and the AGP group had the highest BW among the groups at $\mathrm{d} 42$. Body weight of the $E$. coli + AGP group was significantly higher than that of the $E$. coli + NAT treatment group $(\mathrm{P}<0.01)$. There were no significant differences in feed intake (FI) among treatments, whereas the feed conversion ratio (FCR) was enhanced significantly in chicks fed with AGP or NAT compared with the control group at $42 \mathrm{~d}$ of age. E. coli decreased the FCR in all infected groups, even if supplemented by AGP or NAT $(\mathrm{P}<0.01)$.

The antibody titers against IB, ND, and IBD following vaccination indicate a more significant beneficial effect of NAT supplementation than $\mathrm{CON}$ and $E$. coli infected groups (Table 3 ); the antibody titers from NAT group were increased significantly $(\mathrm{P}<0.01)$ compared with those from the AGP and CON groups. The E. coli-infected group had the weakest immune response to IB, ND, and IBD in terms of vaccine titers $(\mathrm{P}<0.01)$, when compared with $\mathrm{CON}, \mathrm{AGP}$, and NAT groups.

E. coli infection caused a decrease in plasma albumin concentration compared with other treatments; however, this variable increased in the AGP and $\mathrm{CON}$ groups compared with $E$. coli-infected group $(\mathrm{P}<0.01)$ (Table 4).

Table 2 - Effect of dietary treatments on performance of broilers

\begin{tabular}{|c|c|c|c|c|c|c|c|c|}
\hline \multirow{2}{*}{ Item } & \multicolumn{6}{|c|}{ Dietary treatment } & \multirow{2}{*}{ P-value } & \multirow{2}{*}{ SEM } \\
\hline & $\mathrm{CON}$ & E. coli & AGP & NAT & E. coli $+\mathrm{AGP}$ & E. coli + NAT & & \\
\hline \multicolumn{9}{|c|}{ Average body weight (g) } \\
\hline Day 1 & 45.20 & 45.60 & 46.20 & 45.80 & 46.20 & 46.00 & 0.880 & 0.254 \\
\hline Day 14 & $435.00 \mathrm{~b}$ & $428.00 \mathrm{~b}$ & $453.40 \mathrm{a}$ & $453.20 \mathrm{a}$ & $433.40 \mathrm{~b}$ & $432.40 \mathrm{~b}$ & $<0.0001$ & 2.107 \\
\hline Day 21 & $796.40 \mathrm{~b}$ & $740.20 \mathrm{~d}$ & $843.20 \mathrm{a}$ & $805.40 \mathrm{~b}$ & $780.00 \mathrm{c}$ & $775.60 \mathrm{c}$ & $<0.0001$ & 6.029 \\
\hline Day 28 & $1315.60 \mathrm{~d}$ & $1255.80 \mathrm{f}$ & $1365.60 \mathrm{a}$ & $1355.20 \mathrm{~b}$ & $1325.40 \mathrm{c}$ & $1305.20 \mathrm{e}$ & $<0.0001$ & 6.766 \\
\hline Day 35 & $1795.20 \mathrm{~b}$ & $1550.60 \mathrm{~d}$ & $1844.60 \mathrm{a}$ & $1801.80 \mathrm{~b}$ & $1794.20 \mathrm{~b}$ & $1716.60 \mathrm{c}$ & $<0.0001$ & 18.394 \\
\hline Day 42 & $2205.20 \mathrm{c}$ & $2075.00 \mathrm{f}$ & $2451.20 \mathrm{a}$ & $2405.60 b$ & $2151.80 \mathrm{~d}$ & $2110.60 \mathrm{e}$ & $<0.0001$ & 27.081 \\
\hline \multicolumn{9}{|c|}{ Feed intake (g) } \\
\hline $0-42$ days & 3969.52 & 4046.18 & 3985.71 & 3925.97 & 4088.06 & 4089.37 & 0.3197 & 25.148 \\
\hline \multicolumn{9}{|l|}{$\mathrm{FCR}(\mathrm{g} / \mathrm{g})$} \\
\hline $0-42$ days & $1.80 \mathrm{~b}$ & $1.95 \mathrm{a}$ & $1.62 \mathrm{c}$ & $1.63 \mathrm{c}$ & $1.90 \mathrm{a}$ & $1.93 \mathrm{a}$ & $<0.0001$ & 0.026 \\
\hline
\end{tabular}

CON - control group, fed a basal diet; $E$. coli - control plus $0.5 \mathrm{~mL}$ of culture containing $10^{8} \mathrm{cfu} / \mathrm{mL}$ of $E$. coli; AGP - control plus $400 \mathrm{mg} / \mathrm{kg}$ bacitracin methylene disalicylate; NAT - control plus a dietary blend of direct-fed microbials (DFM), phytomolecules, glucomannan oligosaccharides, and organic acids (1000 g/t of feed); E. coli + AGP combination of E. coli and AGP group treatments; E. coli + NAT - combination of E. coli and NAT group treatments.

FCR - feed conversion ratio; SEM - standard error of the mean.

Means with different letters within the same row are significantly different $(\mathrm{P}<0.05)$.

Table 3 - Effect of dietary treatments on immune response of broilers at 42 days of age to vaccination against different diseases

\begin{tabular}{|c|c|c|c|c|c|c|c|c|}
\hline \multirow{2}{*}{ Antibody titer } & \multicolumn{6}{|c|}{ Dietary treatment } & \multirow{2}{*}{ P-value } & \multirow{2}{*}{ SEM } \\
\hline & $\mathrm{CON}$ & E. coli & AGP & NAT & E. coli $+\mathrm{AGP}$ & E. coli $+\mathrm{NAT}$ & & \\
\hline ND $(\log 2)$ & $3.66 \mathrm{c}$ & $3.01 \mathrm{e}$ & $4.00 \mathrm{~b}$ & $5.50 \mathrm{a}$ & $3.50 \mathrm{~d}$ & $4.00 \mathrm{~b}$ & $<0.0001$ & 0.131 \\
\hline IB (ELISA) & $9805.83 \mathrm{bc}$ & $9735.83 b c$ & $9970.00 \mathrm{~b}$ & $10612.17 \mathrm{a}$ & $9535.50 \mathrm{c}$ & $9769.83 \mathrm{bc}$ & $<0.0001$ & 74.687 \\
\hline IBD (ELISA) & $243.42 b$ & $154.35 \mathrm{~d}$ & $347.63 a$ & $341.88 \mathrm{a}$ & $185.10 \mathrm{c}$ & $224.90 \mathrm{c}$ & $<0.0001$ & 12.115 \\
\hline
\end{tabular}

CON - control group, fed a basal diet; $E$. coli - control plus $0.5 \mathrm{~mL}$ of culture containing $10^{8} \mathrm{cfu} / \mathrm{mL}$ of $E$. coli; AGP - control plus $400 \mathrm{mg} / \mathrm{kg}$ bacitracin methylene disalicylate; NAT - control plus a dietary blend of direct-fed microbials (DFM), phytomolecules, glucomannan oligosaccharides, and organic acids (1000 g/t of feed); E. coli + AGP combination of $E$. coli and AGP group treatments; $E$. coli + NAT - combination of E. coli and NAT group treatments.

ND - Newcastle disease; IB - infectious bronchitis; IBD - infectious bursal disease; SEM - standard error of the mean.

Means with different letters within the same row are significantly different $(\mathrm{P}<0.05)$. 
Globulin concentration was significantly higher in the NAT group compared with other treatments. Triglyceride was decreased in the NAT group relative to CON group $(\mathrm{P}<0.05)$. Cholesterol concentration increased in all E. coliinfected groups when compared with $\mathrm{CON}$ and was lower in the AGP and NAT groups $(\mathrm{P}<0.01)$. Moreover, NAT treatment caused a decrease in the LDL level compared with all groups inoculated with E. coli. In contrast, the $E$. coli group had the lowest HDL level among all other treatment groups $(\mathrm{P}<0.01)$. Diet supplementation with NAT caused decreases in ALT, GGT, and ALP activity, whereas these parameters were significantly increased in the E. coli-infected group $(\mathrm{P}<0.01)$, when compared with their respective CON.

Breast muscle content was lowest in the E. coli-infected group and highest in the AGP group $(\mathrm{P}<0.01)$ (Table 5). The NAT-treated group showed more breast weight than the control group $(\mathrm{P}<0.01)$. Incorporation of $E$. coli caused decreased liver weight in all infected groups. The NAT and AGP groups had the highest kidney weight $(\mathrm{P}<0.01)$. AGP and NAT supplementation caused an increase in pancreas weight $(\mathrm{P}<0.01)$. The relative weight of the cloacal bursa was higher in the E. coli-infected group than in the CON; however, heart weight decreased due to $E$. coli infection $(\mathrm{P}<0.01)$. AGP treatment resulted in the highest heart weight among all groups. Spleen weight was decreased in the NAT group relative to $\mathrm{CON}$; however, there was an increase in spleen weight in the AGP and CON groups compared with NAT $(\mathrm{P}<0.01)$.

There was no significant treatment effect on ileal height of villus (Table 6). However, significant declines in crypt depth, villus height to crypt depth ratio, and goblet cell number were found in the ilea of birds fed NAT $(\mathrm{P}<0.05)$, when compared with CON. In contrast, the E. coli-treated group had the highest crypt depth $(\mathrm{P}<0.05)$ among all other dietary treatments.

E. coli infection resulted in decreased digestibilities of DM, CP, and GE compared with CON (Table 7). The addition of AGP and NAT to the diet of E. coli-infected birds (E. coli-treated + AGP and E. coli-treated + NAT) improved DM, CP, and CF digestibility relative to E. coliinfected group $(\mathrm{P}<0.05)$. Overall, the AGP group showed the highest nutrient digestibilities among the groups.

Cecal $E$. coli content was significantly higher by $E$. coli infection than CON, but the addition of NAT or AGP decreased E. coli numbers in ceca, when compared with

Table 4 - Effect of dietary treatments on plasma biochemistry and enzymes of broilers at 42 days of age

\begin{tabular}{|c|c|c|c|c|c|c|c|c|}
\hline \multirow{2}{*}{ Item } & \multicolumn{6}{|c|}{ Dietary treatment } & \multirow{2}{*}{ P-value } & \multirow{2}{*}{ SEM } \\
\hline & $\mathrm{CON}$ & E. coli & AGP & NAT & E. coli $+\mathrm{AGP}$ & E. coli + NAT & & \\
\hline Albumin (g/dL) & $1.80 \mathrm{a}$ & $1.12 \mathrm{~d}$ & $1.75 \mathrm{a}$ & $1.63 \mathrm{~b}$ & $1.34 \mathrm{c}$ & $1.37 \mathrm{c}$ & $<0.0001$ & 0.043 \\
\hline Globulin (g/dL) & $1.98 \mathrm{c}$ & $2.68 \mathrm{a}$ & $2.20 \mathrm{~b}$ & $2.81 \mathrm{a}$ & $1.75 \mathrm{~d}$ & $1.95 \mathrm{c}$ & $<0.0001$ & 0.068 \\
\hline Triglyceride (mg/dL) & $134.88 \mathrm{a}$ & $130.33 b$ & $125.33 \mathrm{c}$ & $116.43 \mathrm{e}$ & $115.53 \mathrm{e}$ & $119.39 d$ & $<0.0001$ & 0.229 \\
\hline Cholesterol (mg/dL) & $197.51 \mathrm{a}$ & $200.51 \mathrm{a}$ & $179.56 b$ & $165.17 \mathrm{c}$ & $199.98 \mathrm{a}$ & $198.23 \mathrm{a}$ & $<0.0001$ & 2.290 \\
\hline HDL (mg/dL) & $67.42 \mathrm{c}$ & $63.61 \mathrm{e}$ & $69.51 \mathrm{ab}$ & $65.76 \mathrm{~d}$ & $70.49 \mathrm{a}$ & $68.57 \mathrm{bc}$ & $<0.0001$ & 0.423 \\
\hline $\mathrm{LDL}(\mathrm{mg} / \mathrm{dL})$ & $75.36 \mathrm{~b}$ & $78.08 \mathrm{a}$ & $71.10 \mathrm{~d}$ & $68.28 \mathrm{e}$ & $76.21 \mathrm{~b}$ & $73.05 \mathrm{c}$ & $<0.0001$ & 0.586 \\
\hline ALT (IU/L) & $4.76 \mathrm{a}$ & $5.05 \mathrm{a}$ & $4.83 \mathrm{a}$ & $4.24 b$ & $4.96 \mathrm{a}$ & $3.96 b$ & $<0.0001$ & 0.080 \\
\hline GGT (IU/L) & $170.19 \mathrm{a}$ & $168.56 \mathrm{a}$ & $165.39 b$ & $158.48 \mathrm{~d}$ & $166.40 \mathrm{~b}$ & $163.23 \mathrm{c}$ & $<0.0001$ & 0.680 \\
\hline ALP (U/L) & $160.45 d$ & $169.39 \mathrm{a}$ & $167.39 b$ & $158.43 \mathrm{e}$ & $165.45 \mathrm{c}$ & $166.29 \mathrm{bc}$ & $<0.0001$ & 0.682 \\
\hline
\end{tabular}

CON - control group, fed a basal diet; $E$. coli - control plus $0.5 \mathrm{~mL}$ of culture containing $10^{8} \mathrm{cfu} / \mathrm{mL}$ of $E$. coli; AGP - control plus $400 \mathrm{mg} / \mathrm{kg}$ bacitracin methylene disalicylate; NAT - control plus a dietary blend of direct-fed microbials (DFM), phytomolecules, glucomannan oligosaccharides, and organic acids (1000 g/t of feed); E. coli + AGP combination of $E$. coli and AGP group treatments; E. coli + NAT - combination of E. coli and NAT group treatments.

HDL - high-density lipoprotein; LDL - low-density lipoprotein; ALT - alanine aminotransferase; GGT - $\gamma$-glutamyl transferase; ALP - alkaline phosphatase; SEM - standard error of the mean.

Means with different letters within the same row are significantly different $(\mathrm{P}<0.05)$.

Table 5 - Effect of dietary treatments on relative weights of selected organs of broilers at 42 days of age

\begin{tabular}{|c|c|c|c|c|c|c|c|c|}
\hline \multirow{2}{*}{ Organ $(\mathrm{g} / \mathrm{kg}$ of $\mathrm{BW})$} & \multicolumn{6}{|c|}{ Dietary treatment } & \multirow{2}{*}{ P-value } & \multirow{2}{*}{ SEM } \\
\hline & $\mathrm{CON}$ & E. coli & AGP & NAT & E. coli $+\mathrm{AGP}$ & E. coli $+\mathrm{NAT}$ & & \\
\hline Breast muscle & $24.91 \mathrm{c}$ & $22.79 \mathrm{e}$ & $27.90 \mathrm{a}$ & $26.17 \mathrm{~b}$ & $24.95 \mathrm{c}$ & $23.96 \mathrm{~d}$ & $<0.0001$ & 0.291 \\
\hline Liver & $5.33 b c$ & $5.26 b c$ & $5.92 \mathrm{a}$ & $5.59 \mathrm{ab}$ & $5.08 \mathrm{c}$ & $5.02 \mathrm{c}$ & $<0.0001$ & 0.069 \\
\hline Kidney & $7.25 b$ & $6.93 c$ & $8.19 \mathrm{a}$ & $8.05 \mathrm{a}$ & $7.26 b$ & $7.13 b$ & $<0.0001$ & 0.083 \\
\hline Pancreas & $3.81 \mathrm{bc}$ & $3.50 \mathrm{c}$ & $4.23 \mathrm{a}$ & $3.99 \mathrm{ab}$ & $3.53 \mathrm{c}$ & $3.83 \mathrm{bc}$ & 0.0003 & 0.059 \\
\hline Cloacal bursa & $1.55 \mathrm{~b}$ & $1.85 \mathrm{a}$ & $1.34 \mathrm{c}$ & $1.36 \mathrm{c}$ & $1.55 b$ & $1.66 \mathrm{a}$ & $<0.0001$ & 0.036 \\
\hline Heart & $3.78 \mathrm{~cd}$ & $3.51 \mathrm{e}$ & $4.19 \mathrm{a}$ & $3.96 \mathrm{~b}$ & $3.71 \mathrm{~d}$ & $3.89 \mathrm{bc}$ & $<0.0001$ & 0.039 \\
\hline Spleen & $1.78 \mathrm{a}$ & $1.37 \mathrm{~b}$ & $1.81 \mathrm{a}$ & $1.11 \mathrm{c}$ & $1.38 \mathrm{~b}$ & $1.67 \mathrm{a}$ & $<0.0001$ & 0.049 \\
\hline
\end{tabular}

CON - control group, fed a basal diet; $E$. coli - control plus $0.5 \mathrm{~mL}$ of culture containing $10^{8} \mathrm{cfu} / \mathrm{mL}$ of $E$. coli; AGP - control plus $400 \mathrm{mg} / \mathrm{kg}$ bacitracin methylene disalicylate; NAT - control plus a dietary blend of direct-fed microbials (DFM), phytomolecules, glucomannan oligosaccharides, and organic acids (1000 g/t of feed); E. coli + AGP combination of $E$. coli and AGP group treatments; E. coli + NAT - combination of E. coli and NAT group treatments.

BW - body weight; SEM - standard error of the mean.

Means with different letters within the same row are significantly different $(\mathrm{P}<0.05)$. 
CON $(\mathrm{P}<0.01)$ (Table 8). Birds not deliberately infected with $E$. coli and fed diets containing AGP or NAT showed a significant drop $(\mathrm{P}<0.01)$ in cecal populations of $E$. coli and coliforms when compared to the CON or E. coli groups. Salmonella numbers were higher in the E. coli + NAT group, but lower in the E. coli-infected group. NAT treatment did not alter the cecal bacterial numeration as effectively as AGP, but it remarkably decreased Salmonella, E. coli, and coliform counts compared to the CON group $(\mathrm{P}<0.01)$.

\section{Discussion}

This study was planned to evaluate the effects of a growth-promoting dietary blend and an AGP on performance, blood chemistry, and intestinal characteristics of broilers challenged with $E$. coli.
Results showed that both feed additives (NAT and AGP) led to improved BW and FCR. The findings of this study are consistent with other reports (Parks et al., 2001; Sims et al., 2004). Studies have reported that thyme extract improves FCR and body weight gain (Demir et al., 2003; Lee et al., 2003; Rahimi et al., 2011). Our findings regarding FI are in agreement with those of Adil et al. (2011) and Toghyani et al. (2010), who reported a nonsignificant effect of organic acids and peppermint on feed intake in broiler chicks. Other researchers reported that the addition of dietary probiotics significantly improved BW gain and FCR with no effect on FI throughout the finisher period (Zhang and Kim, 2014). Addition of a Bacillus-based DFM improved FCR in broilers, altered the gastrointestinal microflora, and decreased colonization by pathogenic strains of E. coli and Clostridium perfringens (Lee et al., 2004). It is evident from reports that the use

Table 6 - Effect of dietary treatments on ileal morphology of broilers at 42 days of age

\begin{tabular}{|c|c|c|c|c|c|c|c|c|}
\hline \multirow{2}{*}{ Item } & \multicolumn{6}{|c|}{ Dietary treatment } & \multirow{2}{*}{ P-value } & \multirow{2}{*}{ SEM } \\
\hline & $\mathrm{CON}$ & E. coli & AGP & NAT & E. coli + AGP & E. coli + NAT & & \\
\hline Villus height $(\mu \mathrm{m})$ & 470 & 420 & 454 & 453 & 446 & 428 & 0.8216 & 0.107 \\
\hline Crypt depth $(\mu \mathrm{m})$ & $85 b$ & $98 \mathrm{a}$ & $82 b$ & $74 \mathrm{c}$ & $90 \mathrm{~b}$ & $88 b$ & $<0.0001$ & 0.115 \\
\hline VCR & $5.48 \mathrm{ab}$ & $4.30 \mathrm{~b}$ & $5.53 \mathrm{ab}$ & $6.15 \mathrm{a}$ & $4.99 \mathrm{ab}$ & $4.92 \mathrm{ab}$ & 0.0420 & 0.189 \\
\hline Goblet cell ${ }^{1}$ & $8.76 b c$ & $9.68 \mathrm{a}$ & $8.65 b c$ & $8.26 \mathrm{c}$ & $9.03 \mathrm{ab}$ & $9.06 \mathrm{ab}$ & 0.0038 & 0.113 \\
\hline
\end{tabular}

CON - control group, fed a basal diet; $E$. coli - control plus $0.5 \mathrm{~mL}$ of culture containing $10^{8} \mathrm{cfu} / \mathrm{mL}$ of $E$. coli; AGP - control plus $400 \mathrm{mg} / \mathrm{kg}$ bacitracin methylene disalicylate; NAT - control plus a dietary blend of direct-fed microbials (DFM), phytomolecules, glucomannan oligosaccharides, and organic acids $(1000$ g/t of feed); $E$. coli + AGP combination of E. coli and AGP group treatments; E. coli + NAT - combination of E. coli and NAT group treatments.

VCR - villus height to crypt depth ratio; SEM - standard error of the mean.

Means with different letters within the same row are significantly different $(\mathrm{P}<0.05)$

${ }^{1}$ Number of goblet cells in each $1 \mathrm{~mm}$ of villus length.

Table 7 - Effect of dietary treatments on nutrient digestibility in the ileum of broilers at 42 days of age

\begin{tabular}{|c|c|c|c|c|c|c|c|c|}
\hline \multirow{2}{*}{ Apparent digestibility (\%) } & \multicolumn{6}{|c|}{ Dietary treatment } & \multirow{2}{*}{ P-value } & \multirow{2}{*}{ SEM } \\
\hline & $\mathrm{CON}$ & E. coli & AGP & NAT & E. coli + AGP & E. coli + NAT & & \\
\hline Dry matter & $77.30 \mathrm{abc}$ & $76.29 \mathrm{c}$ & $79.11 \mathrm{a}$ & $78.73 \mathrm{ab}$ & $77.40 \mathrm{abc}$ & $77.12 \mathrm{bc}$ & 0.0250 & 0.282 \\
\hline Crude fat & $83.22 b$ & $78.24 d$ & $85.32 \mathrm{a}$ & $84.26 \mathrm{ab}$ & $81.19 \mathrm{c}$ & $80.20 c$ & $<0.0001$ & 0.436 \\
\hline Crude protein & $71.17 \mathrm{c}$ & $65.12 \mathrm{e}$ & $73.10 \mathrm{~b}$ & $74.23 \mathrm{a}$ & $70.33 c$ & $69.31 \mathrm{~d}$ & $<0.0001$ & 0.511 \\
\hline Gross energy & $81.32 b$ & $75.43 d$ & $85.04 \mathrm{a}$ & $78.40 \mathrm{c}$ & $72.30 \mathrm{e}$ & $70.15 f$ & $<0.0001$ & 0.873 \\
\hline
\end{tabular}

CON - control group, fed a basal diet; $E$. coli - control plus $0.5 \mathrm{~mL}$ of culture containing $10^{8} \mathrm{cfu} / \mathrm{mL}$ of $E$. coli; AGP - control plus $400 \mathrm{mg} / \mathrm{kg}$ bacitracin methylene disalicylate; NAT - control plus a dietary blend of direct-fed microbials (DFM), phytomolecules, glucomannan oligosaccharides, and organic acids $(1000$ g/t of feed); $E$. coli + AGP combination of E. coli and AGP group treatments; E. coli + NAT - combination of E. coli and NAT group treatments.

SEM - standard error of the mean.

Means with different letters within the same row are significantly different $(\mathrm{P}<0.05)$.

Table 8 - Effect of dietary treatments on cecal bacterial count $\left(\log _{10} \mathrm{CFU} / \mathrm{g}\right)$ of broilers at 42 days of age

\begin{tabular}{|c|c|c|c|c|c|c|c|c|}
\hline \multirow{2}{*}{ Item } & \multirow{2}{*}{$\mathrm{CON}$} & \multicolumn{5}{|c|}{ Dietary treatment } & \multirow{2}{*}{ P-value } & \multirow{2}{*}{ SEM } \\
\hline & & E. coli & AGP & NAT & E. coli $+\mathrm{AGP}$ & E. coli + NAT & & \\
\hline Coliforms & $1.70 \mathrm{~b}$ & $2.50 \mathrm{a}$ & $1.05 \mathrm{~d}$ & $1.35 \mathrm{c}$ & $1.42 \mathrm{c}$ & $1.80 \mathrm{~b}$ & $<0.0001$ & 0.079 \\
\hline Salmonella & $1.56 \mathrm{~b}$ & $2.00 \mathrm{a}$ & $1.12 \mathrm{c}$ & $1.15 \mathrm{c}$ & $1.58 \mathrm{~b}$ & $2.00 \mathrm{a}$ & $<0.0001$ & 0.059 \\
\hline E. coli & $2.10 \mathrm{~b}$ & $2.88 \mathrm{a}$ & $1.15 \mathrm{e}$ & $1.40 \mathrm{~d}$ & $1.65 \mathrm{c}$ & $2.08 \mathrm{~b}$ & $<0.0001$ & 0.098 \\
\hline
\end{tabular}

CON - Control group, fed a basal diet; E. coli - control plus $0.5 \mathrm{~mL}$ of culture containing $10^{8} \mathrm{CFU} / \mathrm{mL}$ of $E$. coli; AGP - control plus $400 \mathrm{mg} / \mathrm{kg}$ bacitracin methylene disalicylate; NAT - control plus a dietary blend of direct-fed microbials (DFM), phytomolecules, glucomannan oligosaccharides, and organic acids (1000 g/t of feed); E. coli + AGP combination of $E$. coli and AGP group treatments; E. coli + NAT - combination of E. coli and NAT group treatments.

SEM - standard error of the mean.

Means with different letters within the same row are significantly different $(\mathrm{P}<0.05)$. 
of DFM with Bacillus spp. has an encouraging effect on overall performance and immune status of commercial chicks by helping newly hatched birds to develop a favorable and constant intestinal microfloral population, in terms of microorganisms (Lee et al., 2004; Teo and Tan, 2007; Amerah et al., 2013). It has been suggested that the antimicrobial properties and low $\mathrm{pH}$ of organic acids inhibit pathogenic intestinal bacteria and decrease the level of toxic bacterial products. As a result, energy and protein digestibility is improved; thereby, the weight gain of broiler chickens is improved (Sultan et al., 2015). It seems that enhanced BW might lead to improved FCR in the AGP and NAT-fed groups. It has also been suggested that probiotics can promote poultry performance by improving nutrient uptake by changing the gastrointestinal bacterial community structure and modifying mucin biosynthesis (Gil de los Santos et al., 2005). Organic acids may change the microbial populations in a line with its antimicrobial spectrum of activity (Zhang and Kim, 2014). Better growth rate in the very beginning of the bird lifespan might be due to increased well-proportioned microflora caused by the presence of DFM in the broiler ration (Salim et al., 2013). Routinely, DFM can have direct effects on the intestinal microbiota in many ways, including removal of undesired or pathogenic bacteria, manipulation in cell-mediated immune responses through local mucus, enhancement of the antibody rate in the blood, and promotion of epithelial barrier integrity (Lee et al., 2004). Harmful gut microflora may lead to enhanced cost of energy through modifying the energy rate by consuming reactions such as turnover of proteins inside the gastro intestinal tract of broilers (Yang et al., 2008).

In intensive poultry systems, it is vital to advance immunity to avoid infectious illnesses (Rahimi et al., 2011). Antibody responses are usually used as a measure to estimate the humoral immune system of birds (Ghosh et al., 2012). In the current study, the antibody titers were increased in NAT group, which has proposed that the phytogenic components present in the medicinal plants may be attached to viruses and act as vaccine supporters, and thus, increase the load of antibody titers (Ghosh et al., 2012). Constant use of herbal medicines together, like thymol and carvacrol, may increase cellular and humoral immune responses of birds. Jahanian and Ashnagar (2015) showed an improvement in antibody responses to ND and IBD viruses as a result of dietary MOS supplementation. It seems that supplemental MOS could excellently destroy enteric pathogens, promoting the general immune system, and leading to an improvement in the integrity of the intestinal mucosa. Moreover, many reports have concluded that the humoral response was increased by administration of multistrain probiotics (Amerah et al., 2013; Zhang and Kim, 2014), which might be due to the antimicrobial peptide synthesis in the gut (Salim et al., 2013). Organic acids lower the environmental $\mathrm{pH}$. More of the organic acids will be in the undissociated form. Undissociated organic acids are lipophilic and can diffuse across cell membranes, including those of bacteria and molds. Once in the bacterial cell, the higher $\mathrm{pH}$ of its cytoplasm causes dissociation of the acid, and the resulting reduction in $\mathrm{pH}$ of the cell contents will disrupt enzymatic reactions and nutrient transport systems. Moreover, in the current study, the globulin concentration was increased in the NAT-fed group, which may be due to more antibody synthesis against viruses (Yang et al., 2008).

Cholesterol concentration increased in all E. coliinfected groups and was lower in the AGP and NAT groups. This is plausibly due to allicin, because it was reported that garlic reduces cholesterol biosynthesis by inhibiting the activity of lipogenic enzymes in chickens (Demir et al., 2005). The lipophilic properties and chemical structures of essential oils present in NAT may have a role in enzyme activity functions in the body of broilers (Cross et al., 2007). These findings are in agreement with a report by Jahanian and Ashnagar (2015), who found that feeding prebiotics reduced serum triglyceride concentration in broiler chicks. Organic acid activity will reduce the total microbial load, but will be particularly effective against $E$. coli and other acid-intolerant organisms. However, in contrast to the findings in the current study, Manafi (2015) reported that the levels of albumin, globulin, and total protein, and the activities of ALT and GGT, were not affected by NAT or DFM.

The cloacal bursa plays a vital role in the poultry immune system and the weight of the cloacal bursa in broilers reflects the anatomical response to immune status (Zhang and Kim, 2014). Rahimi et al. (2011) reported that the relative weight of the cloacal bursa was significantly increased by garlic supplementation. Teo and Tan (2007) reported that DFM did not affect cloacal bursa and spleen weights. The higher weight of the cloacal bursa in the $E$. coli group in this study may indicate an infection caused by E. coli (Hashemipour et al., 2013). Rahimi et al. (2011) showed no alterations in the relative weights of spleen and cloacal bursa in broilers fed a diet containing thyme. Moreover, thymol has been described to encourage digestive enzyme secretions like salivary amylase as well as bile acids, gastric and pancreatic enzymes, and intestinal mucosa (Hashemipour et al., 2013). A significant enhance in pancreatic trypsin, amylase, and activities of maltase in broilers might have increased pancreas weight, which 
probably resulted in improvements in performance indices in the current study.

The findings of the current study on crypt depth, goblet cell numbers, and villus height are in agreement with those of Santin et al. (2001), who reported that addition of $S$. cerevisiae cell wall may reduce crypt depth of broilers. Our findings are consistent with those of Bradley et al. (1994), who reported that goblet cell number and crypt depth of the ileal mucosa decreased when broiler diet was supplemented with $S$. cerevisiae. The use of D-mannose to reduce colonization by enteropathogenic bacteria is well known; it blocks the binding of bacterial fimbrial lectins onto gut intestinal receptors containing D-mannose (Santin et al., 2001; Lee et al., 2004). In another study, Garcia et al. (2007) reported that supplementation of diet with formic acid (10,000 ppm) increased villus height and crypt depth in the intestine of broilers. Moreover, Demir et al. (2005) reported that garlic and thyme significantly decreased the ileal depth of crypts in broilers. The results of the present experiments indicate that the reduction in crypt depth in the ileum of broilers in NAT treatment might leave the energy saved by the reduced turnover rate of epithelial cells for lean tissue mass synthesis. This observation can also help to explain the improvements seen in BW and FCR of broilers. Baurhoo et al. (2007) also reported that MOS significantly increased goblet cell numbers. The crypt can be considered as the villus production unit, so a deeper crypt shows faster renewal processes of the intestinal mucosa (Santin et al., 2001), which drives more nutrients towards tissue regeneration than into growth enhancement. In agreement with the reports of Ghosh et al. (2012) and Demir et al. (2005), in our study, villus height was not affected by dietary treatments. It has been reported that in the presence of toxins and by increasing the load of pathogenic bacteria in the gut, villi and crypts get shorter and deeper, respectively, which results in lower absorption of nutrients and more secretory cells (Choct, 2009). Goblet cells also create and secrete compounds of glycoprotein (mucins), which are the main constituents of first-line protection of host against pathogens of intestine (Baurhoo et al., 2009).

The reduction in coliforms of birds in the AGP and NAT groups resulted in positive health responses. Thus, the lower bacterial load of birds in groups fed with AGP or NAT may be linked with the enhanced apparent GE, CP, DM, and CF digestibility. In contrast to the reports of Yang et al. (2008), apparent digestibility of protein and fat was altered significantly by NAT supplementation in this study. Jahanian and Ashnagar (2015) reported that inclusion of MOS in the diet increased the digestibility coefficients of DM and CP. Sultan et al. (2015) also demonstrated that organic acids improve protein digestibility by decreasing endogenous nitrogen loss and ammonia production. Furthermore, Garcia et al. (2007) demonstrated that the apparent ileal digestion of energy, DM, and CP was improved by feeding broilers with diets containing probiotics. However, Zhang and Kim (2014) did not find any difference in the apparent ileal digestion of DM, nitrogen, and energy among different treatments. Persistence of organic acid antimicrobial activity into the jejunum and ileum is also critical to another of its mechanisms of action. Lower microbial proliferation in the jejunum reduces the competition of the microflora with the host for nutrients. This reduction in competition is one of the mechanisms responsible for improved digestibility. In general, the improved intestinal microbial balance in the current study may explain improvements in $\mathrm{DM}, \mathrm{CP}$, and CF digestibility.

It has been reported that birds fed antibiotic as growth promoter show a significant reduction in the number of E. coli (Jang et al., 2007; Rahimi et al., 2011). Bacitracin methylene disalicylate, with proven activity against pathogenic organisms, decreases E. coli and Salmonella load in the digesta and pushes them towards the mucosal surface (Ghosh et al., 2012). However, Teo and Tan (2007) reported that the population of $E$. coli was not influenced by the addition of zinc bacitracin. In vitro study demonstrated that inclusion of thymol and carvacrol in the diet resulted in antimicrobial activity against intestinal microbes such as $C$. perfringens, S. typhimurium, and E. coli (Jang et al., 2007). Thymol has been shown to lessen the coliforms load in GIT of broilers (Cross et al., 2007). Carvacrol is the essential oil of thyme plant that has a motivating impact on the propagation of Lactobacillus (Rahimi et al., 2011). Hydrophobicity is the important aspect of essential oils and their components that enables EO partition into lipids in the bacterial cell wall and mitochondria, aiding their distribution. Carvacrol and thymol are capable to disintegrate the Gram-negative bacterial outer membrane, releasing lipopolysaccharides, increasing the permeability of the cytoplasmic membrane to ATP, and depolarizing the cytoplasmic membrane (Brenes and Roura, 2010). Furthermore, it has been proposed that inclusion of oligosaccharides may have a probiotic-like effect through an increase in lactic acid production, thus enhancing the beneficial bacterial proliferation and dropping the presence of pathogenic Gram-negative bacteria. Moreover, it has been shown that cecal E. coli enumeration was reduced by dietary supplementation with MOS (Baurhoo et al., 2007).

It is also well documented that organic acids are capable of modifying gut microflora communities and, therefore, may support improvement in immunity and 
gut health (Chaveerach et al., 2004; Emami et al., 2013). Sultan et al. (2015) reported that organic acids significantly reduced total Salmonella and E. coli counts in broilers. The specific organic acids remove GIT coliforms through $\mathrm{pH}$ reduction, which is unfavorable for the multiplication of acid-intolerant species such as Salmonella and E. coli (Sultan et al., 2015). In the current study, we confirmed that the dietary inclusion of NAT could decrease the numbers of cecal coliforms and E. coli compared with the control treatment.

\section{Conclusions}

Dietary supplementation with a blend of phytomolecules, direct-fed microbials, and selected organic acids improves performance and feed efficiency in E. coli-challenged broilers and can serve as an effective treatment to alleviate bacterial-induced growth suppression. It is also recommended for use as a potential substitute to growthpromoter antibiotics in commercial broiler farms.

\section{Acknowledgments}

The authors are grateful for the support of the staff and facilities of the Animal Science Department, Agricultural Faculty, Malayer University, Iran.

\section{References}

Adil, S.; Banday, T.; Bhat, G. A.; Salahuddin, M.; Raquib, M. and Shanaz, S. 2011. Response of broiler chicken to dietary supplementation of organic acids. Journal of Central European Agriculture 12:498-508.

Amerah, A. M.; Van Rensburg, C. J.; Plumstead, P. W.; Kromm, C. and Dunham, S. 2013. Effect of feeding diets containing a probiotic or antibiotic on broiler performance, intestinal mucosa-associated avian pathogenic E. coli and litter water-soluble phosphorus. Journal of Applied Animal Nutrition 1:1-7

Applegate, T. J.; Klose, V.; Steiner, T.; Ganner, A. and Schatzmayr, G. 2010. Probiotics and phytogenics for poultry: Myth or reality? The Journal of Applied Poultry Research 19:194-210.

AOAC - Association of Official Analytical Chemists. 2000. Official methods of analysis of AOAC International.15th ed. Horwitz, W., ed. AOAC, Arlington, VA.

AOAC - Association of Official Analytical Chemists. 2003. Official methods of analysis AOAC. 17th ed. Horwitz, W., ed. Arlington, VA.

Attia, Y. A.; Zeweil, H. S.; Alsaffar, A. A. and El-Shafy, A. S. 2011. Effect of non-antibiotic feed additives as an alternative to lavomycin on productivity, meat quality and blood parameters in broilers. Archiv Fur Geflugelkunde 75:40-48.

Baurhoo, B.; Ferket, P. R. and Zhao, X. 2009. Effects of diets containing different concentrations of mannanoligosaccharide or antibiotics on growth performance, intestinal development, cecal and litter microbial populations, and carcass parameters of broilers. Poultry Science 88:2262-2272.
Baurhoo, B.; Phillip, L. and Ruiz-Feria, C. A. 2007. Effects of purified lignin and mannan oligosaccharides on intestinal integrity and microbial populations in the ceca and litter of broiler chickens. Poultry Science 86:1070-1078.

Biggs, P. and Parsons, C. M. 2008. The effects of Grobiotic-P on growth performance, nutrient digestibilities, and cecal microbial populations in young chicks. Poultry Science 87:1796-1803.

Bovera, F.; Lestingi, A.; Iannaccone, F.; Tateo, A. and Nizza, A. 2012. Use of dietary mannanoligosaccharides during rabbit fattening period: Effects on growth performance, feed nutrient digestibility, carcass traits, and meat quality. Journal of Animal Science 90:3858-3866

Bradley, G. L.; Savage, T. F. and Timm, K. I. 1994. The effects of supplementing diets with Saccharomyces cerevisiae var. boulardii on male poult performance and ileal morphology. Poultry Science $73: 1766-1770$

Brenes, A. and Roura, E. 2010. Essential oils in poultry nutrition: Main effects and modes of action. Poultry Science 158:1-14.

Bryant, M. P. and Burkey, L. A. 1953. Cultural methods and some characteristics of some of the more numerous groups of bacteria in the bovine rumen. Journal of Dairy Science 36:205-217.

Casewell, M.; Friis, C.; Marco, E.; McMullin, P. and Phillips, I. 2003. The European ban on growth-promoting antibiotics and emerging consequences for human and animal health. Journal of Antimicrobial Chemotherapy 52:159-161.

Chaveerach, P.; Keuzenkamp, D. A.; Lipman, L. J. A. and van Knapen, F. 2004. Effect of organic acids in drinking water for young broilers on Campylobacter infection, volatile fatty acid production, gut microflora and histological cell changes. Poultry Science 83:330-334.

Choct, M. 2009. Managing gut health through nutrition. British Poultry Science 50:9-15.

Corzo, A.; Loar II, R. E. and Kidd, M. T. 2009. Limitations of dietary isoleucine and valine in broiler chick diets. Poultry Science 88:1934-1938.

Cross, D. E.; McDevitt, R. M.; Hillman, K. and Acamovic, T. 2007. The effect of herbs and their associated essential oils on performance, dietary digestibility and gut microflora in chickens from 7 to 28 days of age. British Poultry Science 48:496-506.

Demir, E.; Sarica, S.; Ozcan, M. A. and Suicmez, M. 2003. The use of natural feed additives as alternatives for an antibiotic growth promoter in broiler diets. British Poultry Science 44:S44-S45.

Demir, E.; Sarica, S.; Ozcan, M. A. and Suicmez, M. 2005. The use of natural feed additives as alternatives to an antibiotic growth promoter in broiler diets. Archiv Fur Geflugelkunde 69:110-116.

Diarra, M. S.; Silversides, F. G.; Diarrassouba, F.; Pritchard, J.; Masson, L.; Brousseau, R.; Bonnet, C.; Delaquis, P.; Bach, S.; Skura, B. J. and Topp, E. 2007. Impact of feed supplementation with antimicrobial agents on growth performance of broiler chickens, Clostridium perfringens and enterococcus counts, and antibiotic resistance phenotypes and distribution of antimicrobial resistance determinants in Escherichia coli isolates. Applied and Environmental Microbiology 73:6566-6576.

Emami, N. K.; Naeini, S. Z. and Ruiz-Feria, C. A. 2013. Growth performance, digestibility, immune response and intestinal morphology of male broilers fed phosphorus deficient diets supplemented with microbial phytase and organic acids. Livestock Science 157:506-513.

Fernandez, A.; Lara, C.; Loste, A. and Marca, M. C. 2002. Efficacy of calcium fosfomycin for the treatment of experimental infection of broiler chickens with Escherichia coli O78:K80. Veterinary Research Communications 26:427-436.

Garcia, V.; Catala-Gregori, P.; Hernandez, F.; Megias, M. D. and Madrid, J. 2007. Effect of formic acid and plant extracts on growth, nutrient digestibility, intestine mucosa morphology, and 
meat yield of broilers. The Journal of Applied Poultry Research 16:555-562.

Gaskins, H. R.; Collier, C. T. and Anderson, D. B. 2002. Antibiotics as growth promotants: Mode of action. Animal Biotechnology 13:29-42.

Ghosh, T. K.; Haldar, S.; Bedford, M. R.; Muthusami, N. and Samanta, I. 2012. Assessment of yeast cell wall as replacements for antibiotic growth promoters in broiler diets: effects on performance, intestinal histo-morphology and humoral immune responses. Journal of Animal Physiology and Animal Nutrition 96:275-284.

Gil de los Santos, J. R.; Storch, O. B. and Gil-Turnes, C. 2005. Bacillus cereus var. Toyoii and Saccharomyces boulardii increased feed efficiency in broilers infected with Salmonella enteritidis. British Poultry Science 46:494-497.

Hahn, T. W.; Lohakare, J. D.; Lee, S. L.; Moon, W. K. and Chae, B. J. 2006. Effects of supplementation of $\beta$-glucans on growth performance, nutrient digestibility, and immunity in weanling pigs. Journal of Animal Science 84:1422-1428.

Hashemipour, H.; Kermanshahi, H.; Golian, A. and Veldkamp, T. 2013. Effect of thymol and carvacrol feed supplementation on performance, antioxidant enzyme activities, fatty acid composition, digestive enzyme activities, and immune response in broiler chickens. Poultry Science 92:2059-2069.

Jahanian, R. and Ashnagar, M. 2015. Effect of dietary supplementation of mannan-oligosaccharides on performance, blood metabolites, ileal nutrient digestibility, and gut microflora in Escherichia coli-challenged laying hens. Poultry Science 94:2165-72. doi: $10.3382 / \mathrm{ps} / \mathrm{pev} 180$.

Jang, I. S.; Ko, Y. H.; Kang, S. Y. and Lee, C. Y. 2007. Effect of a commercial essential oil on growth performance, digestive enzyme activity and intestinal microflora population in broiler chickens. Animal Feed Science and Technology 134:304-315.

Jayaraman, S.; Thangavel, G.; Kurian, H.; Mani, R.; Mukkalil, R. and Chirakkal, H. 2013. Bacillus subtilis PB6 improves intestinal health of broiler chickens challenged with Clostridium perfringensinduced necrotic enteritis. Poultry Science 92:370-374.

Lee, K. W.; Everts, H. and Beynen, A. C. 2004. Essential oils in broiler nutrition. International Journal of Poultry Science 3:738-752.

Lee, K.W.; Everts, H.; Kappert, H. J.; Yeom, K. H. and Beyen, A. C. 2003. Dietary carvacrol lowers body weight gain but improve feed conversion in female broiler chickens. Journal of Applied Poultry Research 12:394-399.

Manafi, M. 2015. Comparison study of a natural non-antibiotic growth promoter and a commercial probiotic on growth performance, immune response and biochemical parameters of broiler chicks. Journal of Poultry Science 52:274-281.

Parks, C. W.; Grimes, J. L.; Ferket, P. R. and Fairchild, A. S. 2001. The effect of mannanoligosaccharides, bambermycins and virginiamycin on performance of large white male market turkey. Poultry Science 80:718-723.

Quinn, P. J.; Carter, M. E.; Markey, B. and Carter, G. R. 1994. Bacillius species. p.178-183. In: Clinical veterinary microbiology. Mosby, Wolfe Publishing, London.
Rahimi, S.; Teymori Zadeh, Z.; Torshizi, K.; Omidbaigi, R. and Rokni, H. 2011. Effect of the three herbal extracts on growth performance, immune system, blood factors and intestinal selected bacterial population in broiler chickens. Journal of Agricultural Science and Technology 13:527-553.

Salim, H. M.; Kang, H. K.; Akter, N.; Kim, D. W.; Kim, J. H.; Kim, M. J.; Na, J. C.; Jong, H. B.; Choi, H. C.; Suh, O. S. and Kim, W. K. 2013. Supplementation of direct-fed microbials as an alternative to antibiotic on growth performance, immune response, cecal microbial population, and ileal morphology of broiler chickens. Poultry Science 92:2084-2090

Santin, E.; Maiorka, A. and Macari, M. 2001. Performance and intestinal mucosa development of broiler chickens fed diets containing Saccharomyces cerevisiae cell wall. The Journal of Applied Poultry Research 10:236-244.

Shanmugasundaram, R.; Sifri, M. and Selvaraj, R. K. 2013. Effect of yeast cell product supplementation on broiler cecal microflora species and immune responses during an experimental coccidial infection. Poultry Science 92:1195-1201.

Sims, M. D.; Dawson, K. A.; Newman, K. E.; Spring, P. and Hooge, D. M. 2004. Effects of dietary mannan oligosaccharide, bacitracin methylene disalicylate, or both on the live performance and intestinal microbiology of turkeys. Poultry Science 83:1148-1154.

Sultan, A.; Ullah, T.; Khan, S. and Khan, R. U. 2015. Effect of organic acid supplementation on the performance and ileal microflora of broiler during finishing period. Pakistan Journal of Zoology 47:635-639.

Teo, A. Y. and Tan, H. M. 2007. Evaluation of the performance and intestinal gut microflora of broilers fed on corn-soy diets supplemented with Bacillus subtilis PB6 (CloSTAT). The Journal of Applied Poultry Research 16:296-303.

Toghyani, M.; Toghyani, M.; Gheisari, A.; Ghalamkari, G. and Mohammadrezaei, M. 2010. Growth performance, serum biochemistry and blood hematology of broiler chicks fed different levels of black seed (Nigella sativa) and peppermint (Mentha Piperita). Livestock Science 129:173-178.

Williams, C. H.; David, D. J. and Iismaa, O. 1962. The determination of chromic oxide in faeces samples by atomic absorption spectrophotometry. Journal of Agricultural Science 59:381-385.

Xu, Z. R.; Hu, C. H.; Xia, M. S.; Zhan, X. A. and Wang, M. Q. 2003. Effects of dietary fructooligosaccharide of digestive enzyme activities, intestinal microflora and morphology of male broilers. Poultry Science 82:1030-1036.

Yang, Y.; Iji, P. A.; Kocher, A.; Thomson, E.; Mikkelsen, L. L. and Choct, M. 2008. Effects of mannanoligosaccharide in broiler chicken diets on growth performance, energy utilisation, nutrient digestibility and intestinal microflora. British Poultry Science 49:186-194.

Zhang, Z. F. and Kim, I. H. 2014. Effects of multistrain probiotics on growth performance, apparent ileal nutrient digestibility, blood characteristics, cecal microbial shedding, and excreta odor contents in broilers. Poultry Science 93:364-370. 